\title{
Does practice make perfect?
}

\author{
Stephen R. Hazelrigg, MD
}

\author{
From the Division of Cardiothoracic Surgery, SIU School of Medicine, Springfield, Ill. \\ Disclosures: Author has nothing to disclose with regard to commercial support. \\ Received for publication Oct 23, 2018; accepted for publication Oct 23, 2018. \\ Address for reprints: Stephen R. Hazelrigg, MD, Division of Cardiothoracic Surgery, SIU School of Medicine, \\ 701 N 1st St, Suite D252, Springfield, IL 62702 (E-mail: shazelrigg@ siumed.edu). \\ J Thorac Cardiovasc Surg 2019;157:790 \\ $0022-5223 / \$ 36.00$ \\ Copyright (c) 2018 by The American Association for Thoracic Surgery \\ https://doi.org/10.1016/j.jtcvs.2018.10.109
}

The old adage "practice makes perfect" is generally regarded as accurate and applicable to surgical procedures. The article "Ivor Lewis Minimally Invasive Esophagectomy for Esophageal Cancer: An Excellent Operation That Improves With Experience" 1 would suggest that it is definitely applicable to minimally invasive esophagectomy (MIE). These data represent a single surgeon's 8-year, 170case journey with this operation. Improvements in outcomes came largely in the fourth quarter of his experience or in the last 2 years.

It should be noted that given the relatively small numbers of esophagectomies performed by even busy surgeons, it only requires changing outcomes in a few patients to start to see some statistical changes. Also, esophagectomy for cancer represents one of the more variable and technically challenging operations in general thoracic surgery. There are multiple variations of operations performed and, frankly, often a paucity of good data to help drive decisions on how to best do these operations. Now with MIE, we have introduced even another twist, and, in addition, there are multiple different operative procedures referred to as MIE.

The data presented confirm that MIE is a safe operation. However, it would appear that even with an experienced surgeon with years of experience performing other minimally invasive procedures in the chest (eg, video-assisted thoracoscopic surgery), there is still a long learning curve. To help bring some perspective to typical volumes for esophagectomy, in a recent Society of Thoracic Surgeons database evaluation of 167 centers, only 70 participants $(42 \%)$ performed 5 or more esophagectomies per year at that hospital.

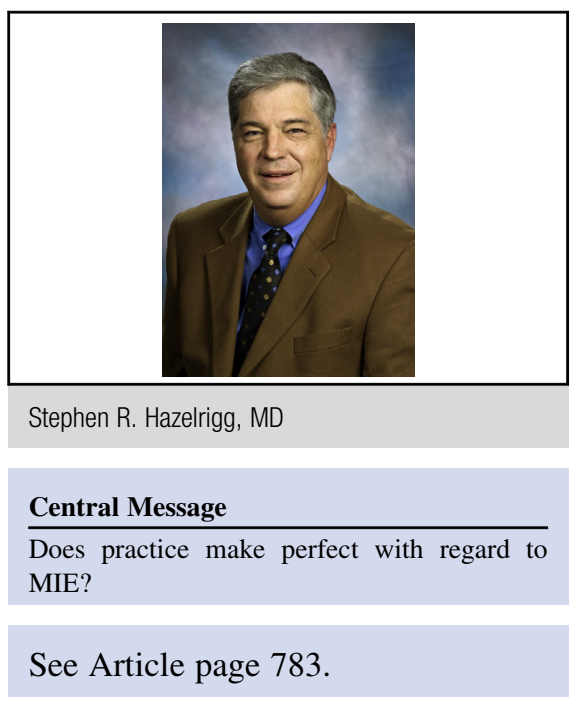

Outcomes and readmissions are primarily driven by postoperative complications. On the basis of these data, it would appear that it would take most surgeons awhile, especially if they are not high-volume esophageal surgeons, to work completely through the learning curve, allowing them to achieve the excellent results desired. The results achieved in this article are similar overall to the Society of Thoracic Surgeons database results. ${ }^{2}$ For example, for the years 2012 to 2014, the operative mortality rate in the database was $3.1 \%$, approximately the same reported here. Given the large learning curve, relative infrequency of operations in most centers, and similar overall results, each surgeon performing esophagectomy will need to decide if performing MIE is the correct choice.

\section{References}

1. White A, Kucukak S, Lee DN, Mazzola E, Zhang Y, Swanson SJ. Ivor Lewis minimally invasive esophagectomy for esophageal cancer: an excellent operation that improves with experience. J Thorac Cardiovasc Surg. 2019;157:783-9.

2. Society of Thoracic Surgeons General Thoracic Surgery Database Task Force. The Society of Thoracic Surgeons composite score for evaluation esophagectomy for esophageal cancer. Ann Thorac Surg. 2017;103:1661-7. 